\title{
Simple hyperplasia versus proliferative endometrium: stereological study
}

\author{
Hiperplasia simples versus endométrio proliferativo: estudo estereológico
}

\author{
Elyzabeth Avvad-Portari ${ }^{1,2}$ \\ Nádia D. Gomes ${ }^{1}$ \\ Carlos A. Mandarim-de-Lacerda ${ }^{2}$
}

\begin{tabular}{|c|c|}
\hline $\begin{array}{l}\text { Simple hyperplasia } \\
\text { Proliferative endometrium } \\
\text { Stereology }\end{array}$ & $\begin{array}{l}\text { The diagnosis of some forms of hyperplastic endometrium continues to present difficulties for } \\
\text { the practicing pathologist. One of the major problems is the lack of a standard terminology } \\
\text { for endometrial classification. Therefore, morphometrical techniques could help the accurate } \\
\text { diagnosis. Thirteen samples of endometrium with simple hyperplasia and thirteen samples of } \\
\text { proliferative endometrium were analyzed by light microscopy and stereology. We determined } \\
\text { the volume density, the surface density and the length density ( } \mathrm{Vv}, \mathrm{Sv}, \mathrm{Lv} \text { ) of the glands } \\
\text { (epithelium and lumen) and the stroma. Volume densities of the epithelium and lumen as } \\
\text { well as the surface density of the inner perimeter of the glands were greater in simple } \\
\text { hyperplasia than in proliferative endometrium ( } \mathrm{p}<0.05) \text {. But the volume density of the } \\
\text { stroma was greater in proliferative endometrium than in simple hyperplasia ( } p<0.05) \text {. The } \\
\text { length density of the glands and the surface density of the outer perimeter were not different } \\
\text { comparing these two groups. Present results agree with previous studies that have pointed } \\
\text { out the importance of quantitative parameters in the diagnosis of the endometrial } \\
\text { pathologies offering new stereological parameters to this analysis. }\end{array}$ \\
\hline
\end{tabular}

resumo

0 diagnóstico de algumas formas de hiperplasia endometrial é freqüentemente difícil porque há controvérsias sobre os critérios histológicos. Por isso, técnicas morfométricas poderiam auxiliar na acurácia deste diagnóstico. Com microscopia óptica e estereologia foram estudados treze casos em cada grupo: hiperplasia simples e endométrio proliferativo. As glândulas (epitélio e luz) e 0 estroma foram estudados, determinando-se as densidades de volume, de superfície e de comprimento ( $\mathrm{VV}, \mathrm{Sv}, \mathrm{Lv})$. As densidades de volume do epitélio e luz glandular, bem como a densidade de superfície interna das glândulas, foram maiores na hiperplasia simples quando comparadas com 0 endométrio proliferativo $(p<0,05)$. No entanto, a densidade de volume do estroma foi maior no endométrio proliferativo quando comparado com a hiperplasia simples. A densidade de comprimento e a densidade de superfície externa não foram diferentes comparando estes dois grupos. Os resultados obtidos concordam com estudos prévios que demonstraram a importância de parâmetros quantitativos no diagnóstico das patologias do endométrio, oferecendo novos parâmetros estereológicos para esta análise.

\section{unitermos}

Hiperplasia simples Endométrio proliferativo Estereologia

\section{Introduction}

Endometrial adenocarcinoma is one of the most common malignant neoplasms of the female genital tract, considered to have a hormone-dependent malignancy $(13,21,22)$. The subtype estrogendependent carcinoma is frequently related to the endometrial hyperplasia, that constitutes a heterogeneous group of abnormal proliferations, some of which are precursors of endometrial carcinoma (23, 24, 25).

The endometrial hyperplasia and the welldifferentiated adenocarcinoma might represent distinct stages of the same disease (11). Among the proliferative
1. Department of Pathology and Laboratories, State University of Rio de Janeiro (UFRI), Brazil. 2. Laboratory of Morphometry and Cardiovascular Morphology, State University of Rio de Janeiro (Ueri), Brazil. 
states of the endometrium there is a morphologic continuum, which includes the proliferative endometrium; persistent proliferative endometrium related to anovulatory cycles; simple and complex hyperplasia with and without atypias; well-differentiated adenocarcinoma and poorly differentiated adenocarcinoma (29).

The typical and extreme cases of this spectrum in the benign and malignant aspects are easily diagnosed, but there are cases when the diagnosis becomes extremely difficult. In the morphologic continuum there are two points of diagnostic difficulty to the pathologist. One of them is how to define the lesions that are, in fact, malignant neoplastic proliferations (well-differentiated adenocarcinoma) of the ones that are potentially malignant (atypical hyperplasia). The other problem is to establish the difference, with reasonable certainty, between the nonneoplastic proliferative endometrium and simple hyperplasia.

In the daily practice, the differential diagnosis more frequently imposed happens between the proliferative endometrium and the simple hyperplasia, particularly in the perimenopause women $(13,19)$.

The subjectivity in the histopathological diagnosis is oppressed by the lack of parameters that are fully accepted in the diagnosis of hyperplasia. Therefore, there are many classifications of endometrial hyperplasia, which causes the misunderstanding of the different descriptions $(11,16)$.

Facing the problem of reproducibility, the lack of diagnostic agreement emphasizes the obvious need of objective criteria. In the recent years, new effective methods in defining borderline lesions have been used. The morphometry offers us the possibility of quantifying microscopically the morphologic alterations that occur in cells and tissues in every pathological process and precisely establish the degree of pathological alterations (8). This methodology shows that the reproducibility and consistency of quantitative microscopic classifications are superior to those of routine subjective grading $(1,3)$.

Therefore, the present work aims to study quantitatively simple hyperplasia and normal proliferative endometrium cases in order to help the diagnosis of endometrial hyperplasia.

\section{Methods}

Thirteen formalin-fixed, paraffin-processed blocks of proliferative endometrium and 13 of simple hyperplasia were obtained from the files of Department of Pathology (Uerj).

The age of the patients ranged from 40 to 55 years old and specimens were obtained by biopsy.

Two pathologists reviewed the slides.

Five $\mu \mathrm{m}$-thick sections were cut from each paraffin block and stained with haematoxylin and eosin.

The stereological study was performed at the Laboratory of Morphology and Morphometry, Institute of Biology, Uerj. Five microscopical fields of each section were observed respecting the Köhler lighting, with a 400 times magnification in a Nikon Alphaphoto microscope. The scope of the stereology is to determine three-dimensional quantitative parameters of morphological structures from bi-dimensional counts. For that, stereology uses geometry and probabilistic statistics and is determined from counts of test-points and test-intersections applying some previously defined mathematical formulas. The evaluation of many stereological parameters needs counts on isotropic and random sections as requirement. A test-system is a system of lines (straight or curve lines) and points. This should be superimposed on a morphologic image for the stereological count (17). In this study, we used the testsystem named M42 by Weibel et al. (27), that has 42 testpoints, the test-line measures $21 \mathrm{~d}$ and the test-area measures $36.36 \mathrm{~d}^{2}$ (Figure 1). The M42 test-system was mounted into the $\times 10$ CFW Nikon eyepiece (Tonbridge ${ }^{\circledR}$, England) $(18,28)$.

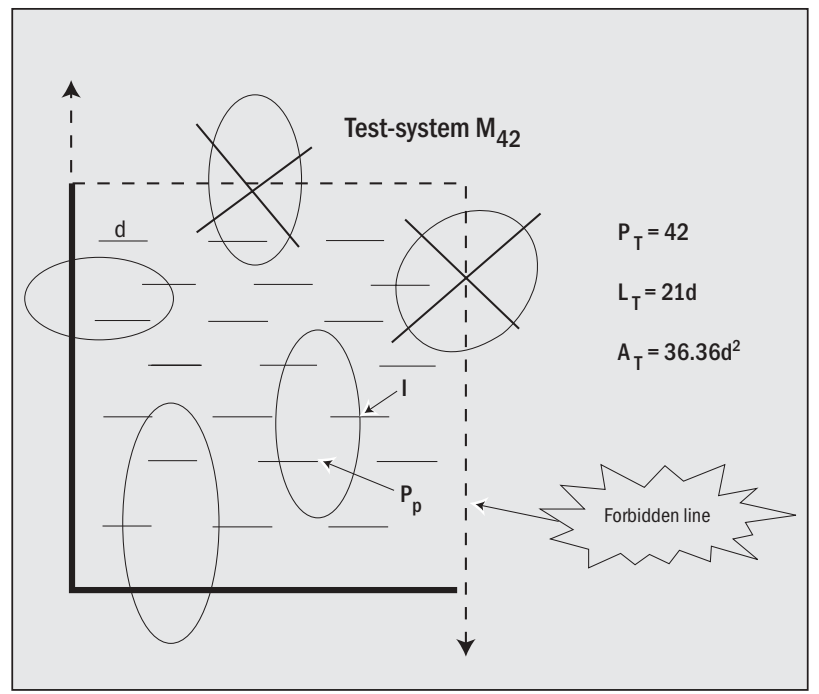

Figure 1 - Test-system M42. All structures falling on the 'forbidden line' (dotted lines) are not counted to avoid overestimation. The short line length ' $d$ ' calibrates this test-system and its extremes are considered test-points (Pp), all short lines are the test-line $\left(L_{T}\right)$, and the test-area $\left(A_{T}\right)$ is the area inside the frame 
Using the stereology, parameters were achieved. Endometrial glands and stroma features were calculated separately. Volume densities of the glands (lumen, epithelium) and stroma were determined by point counting. The glandular outer and inner surface densities were calculated by intersections counting.

a) Volume densities ( $V v)$ (epithelium, stroma and lumen): $V v=\frac{P_{p}}{P_{T}} \%$

$P_{p}$ is the number of test points in the structure, $P_{T}-$ number of total test points.

b) Surface densities (Sv) of the inner and outer endometrial glands:

$\mathrm{Sv}=\frac{21}{\mathrm{~L}_{\mathrm{T}}}\left(\mathrm{mm}^{2} / \mathrm{mm}^{3}\right)$

where I are the intersections of the inner and outer glandular surfaces with the test line, $\mathrm{L}_{T}$ is the length of the test-line.

c) Length density (Lv) of the glands:

$L v=2 Q_{A}\left(\mathrm{~mm} / \mathrm{mm}^{3}\right)$

$Q_{A}$ is the number of the glandular profiles in the test area.

The coefficient of error for the stereological estimates was calculated as the ratio between the standard error and mean. Quantitative differences of stereological parameters comparing the two groups were analyzed with non-parametric two-sided Mann-Whitney test with the significant level $(p)$ at 0.05 .

\section{Results}

The Table and Figures $\mathbf{2}$ to $\mathbf{5}$ summarize the results. All parameters were different comparing the simple hyperplasia and the proliferative endometrium except for Sv[outer] and Lv[gland].

The $\mathrm{Vv}$ [epithelium] was $26.8 \%$ greater in simple hyperplasia than in proliferative endometrium $(p<0.05)$ (Figure 2). The Vv[lumen] was $125.41 \%$ greater in simple hyperplasia than in proliferative endometrium $(p<0,05)$ (Figure 3), whereas Vv[stroma] was $37.6 \%$ smaller in simple hyperplasia than in proliferative endometrium groups $(p<0.05)$ (Figure 4). The Sv[inner] was $31.0 \%$ greater in simple hyperplasia than in proliferative endometrium $(p<0.05)$ (Figure 5).

\section{Discussion}

The morphometric measurement (thickness and nuclear parameters of glandular epithelium) seemed to be not very important to establish the difference between normal and pathological endometrium $(2,6,7,10,12$, 20 , and 26). On the other hand, the stereological measures have shown higher correlation with endometrial pathologies. The $\mathrm{Vv}$ [epithelium] was the best discriminant factor between hyperplasia and adenocarcinoma $(1,6)$.

The interpretation of the quantitative results from hyperplasia and proliferative endometrium is difficult by the lack of researches about this subject. In the present study, the differences of the $\mathrm{Vv}$ [epithelium], $\mathrm{Vv}$ [stroma], Vv[lumen] and Sv[inner] were statistically significant comparing the simple hyperplasia with the proliferative endometrium. The Sv[outer] and the Lv[gland] did not present significant difference between these two groups. Our results are similar to the recent stereological work that studied many groups of endometrium samples, including the normal proliferative group and simple hyperplasia (1).
Table

$\begin{array}{lc}\text { Parameters } & \begin{array}{c}\text { Proliferative } \\ \text { endometrium }\end{array} \\ \text { Vv[epithelium] \% } & 25.88 \pm 3.99 \\ \text { Vv[lumen] \% } & 12.87 \pm 4.20 \\ \text { Vv[stroma] \% } & 61.22 \pm 7.80 \\ \text { Sv[inner] \% } & 7.44 \pm 1.93 \\ \text { Sv[outer] \% } & 12.19 \pm 1.16 \\ \text { Lv[gland] 1/ } \mathrm{mm}^{3} & 36.06 \pm 6.09\end{array}$
and simple hyperplasia

\section{Statistical analysis of the stereological parameters between the proliferative endometrium}




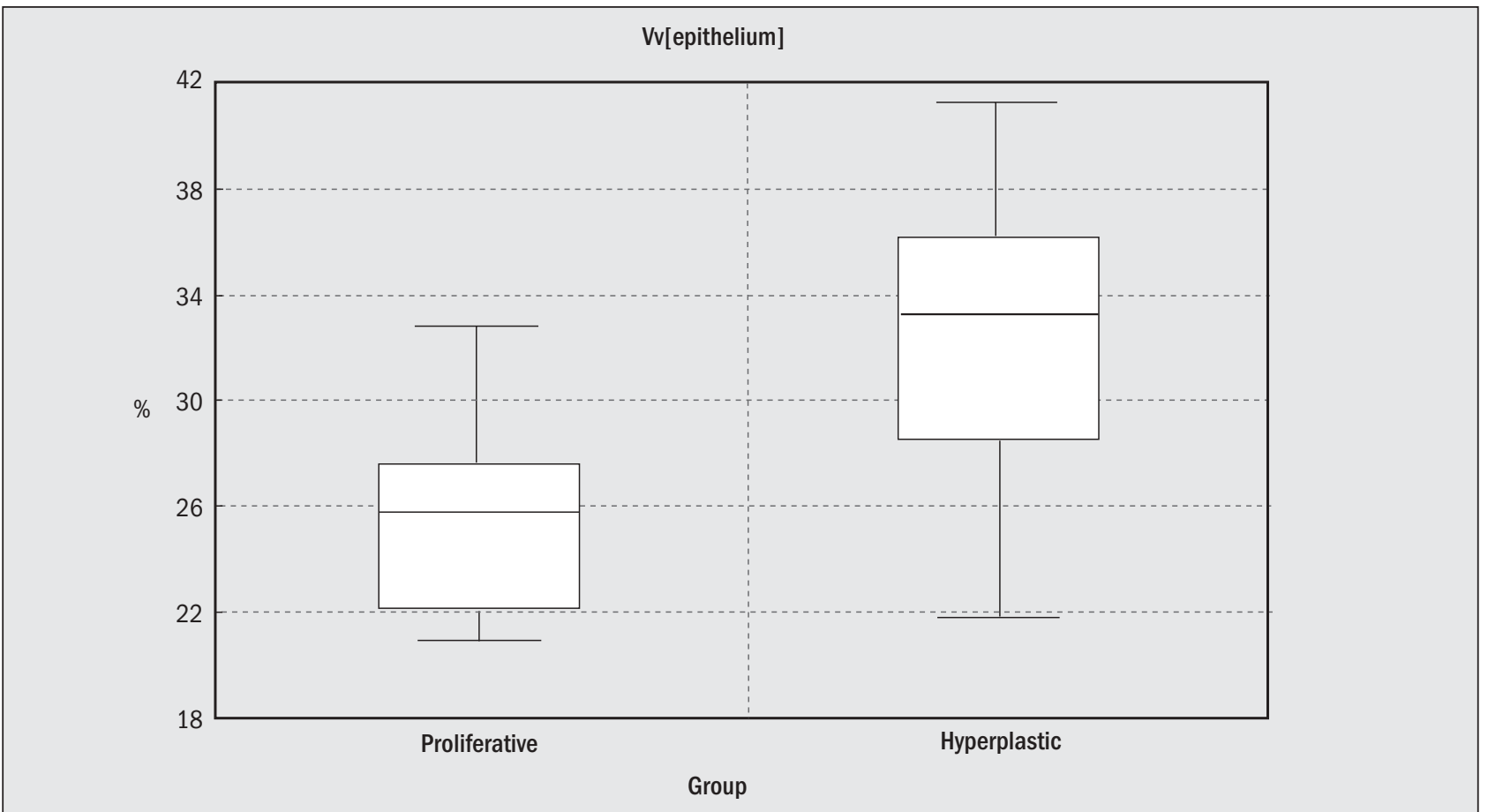

Figure 2 - Boxplot of the volume density of the glandular epithelium comparing the proliferative endometrium and the simple hyperplasia. Difference is significant $(p<0.05)$

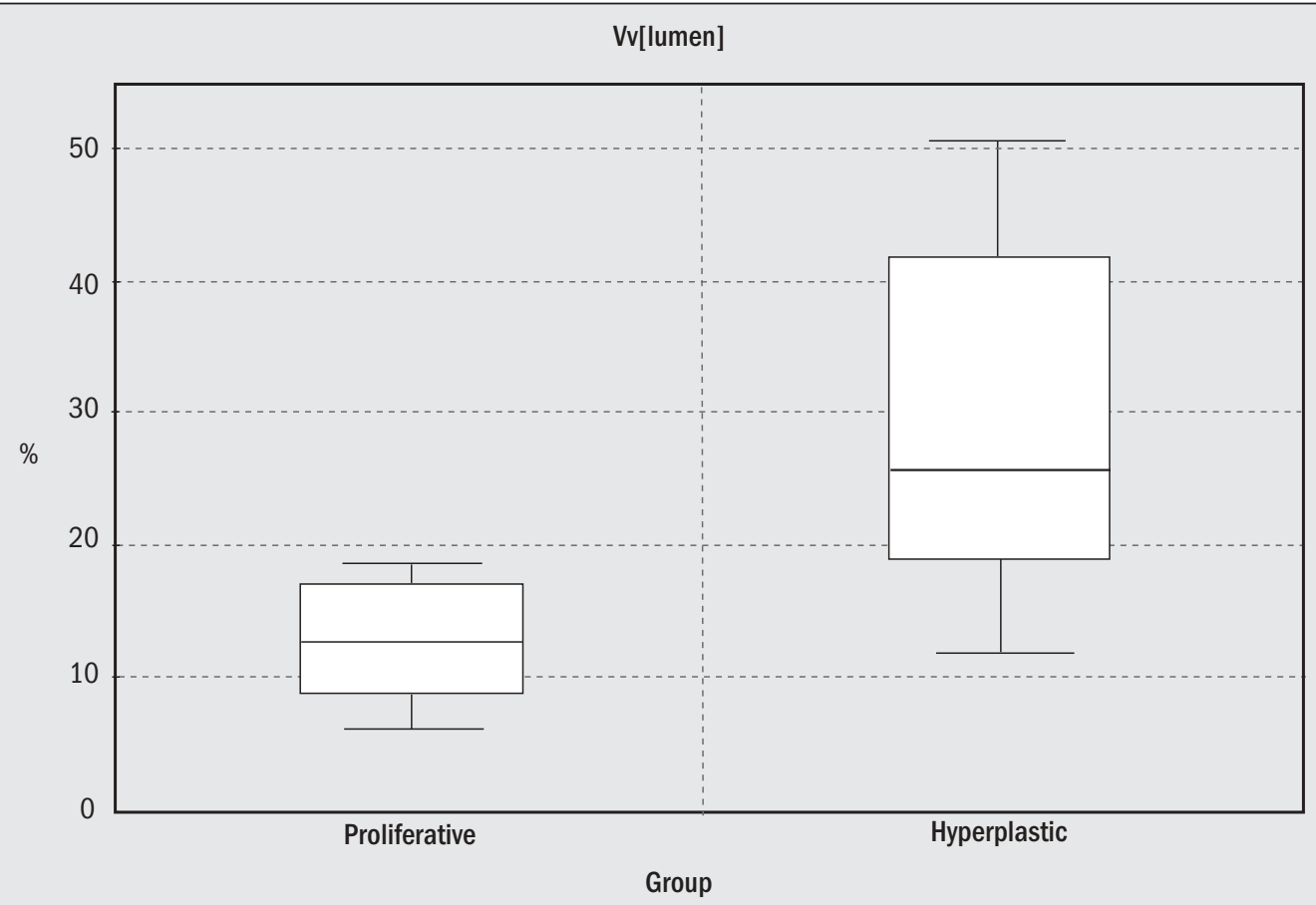

Figure 3 - Boxplot of the volume density of the glandular lumen comparing the proliferative endometrium and the simple hyperplasia. Difference is significant $(p<0.05)$

The Vv[epithelium] was greater in simple hyperplasia than in proliferative endometrium. This difference could be explained even by the increase of the glands as well as by the epithelium hyperplasia, reflecting the typical stratified or pseudo-stratified epithelium observed in the cases of simple hyperplasia. Because of this some authors have described diagnostic discriminative power of the $\operatorname{Vv}[$ epithelium] and its importance in the architectural changes that occur in the endometrium $(1,6)$. Three-dimensional knowledge (architectural features) is considered more important than the linear morphometric nuclear evaluation in the discrimination of the endometrial lesions (4-7, 20, and 26). 


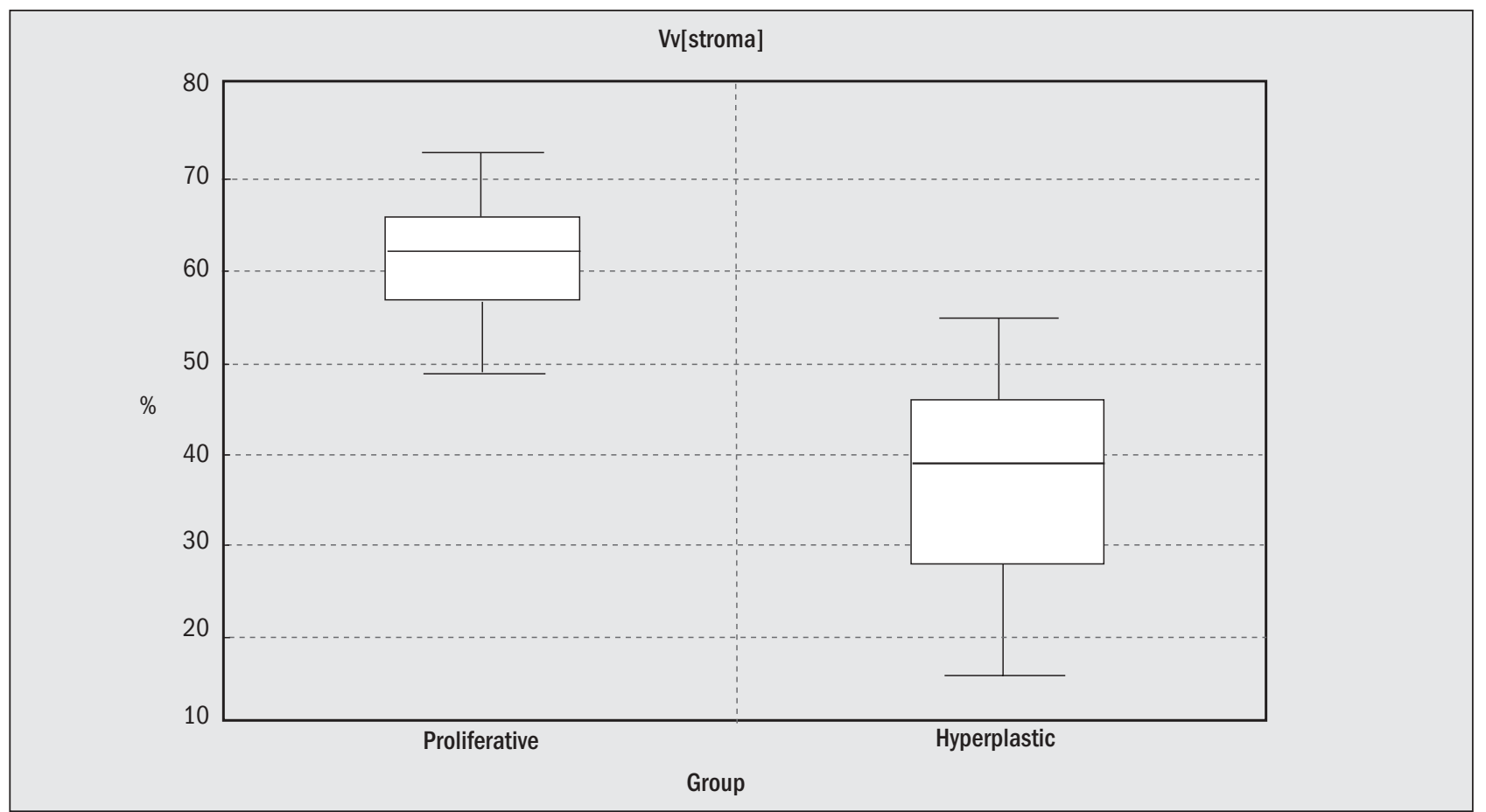

Figure 4 - Boxplot of the volume density of the stroma comparing the proliferative endometrium and the simple hyperplasia. Difference is significant $(p<0.05)$

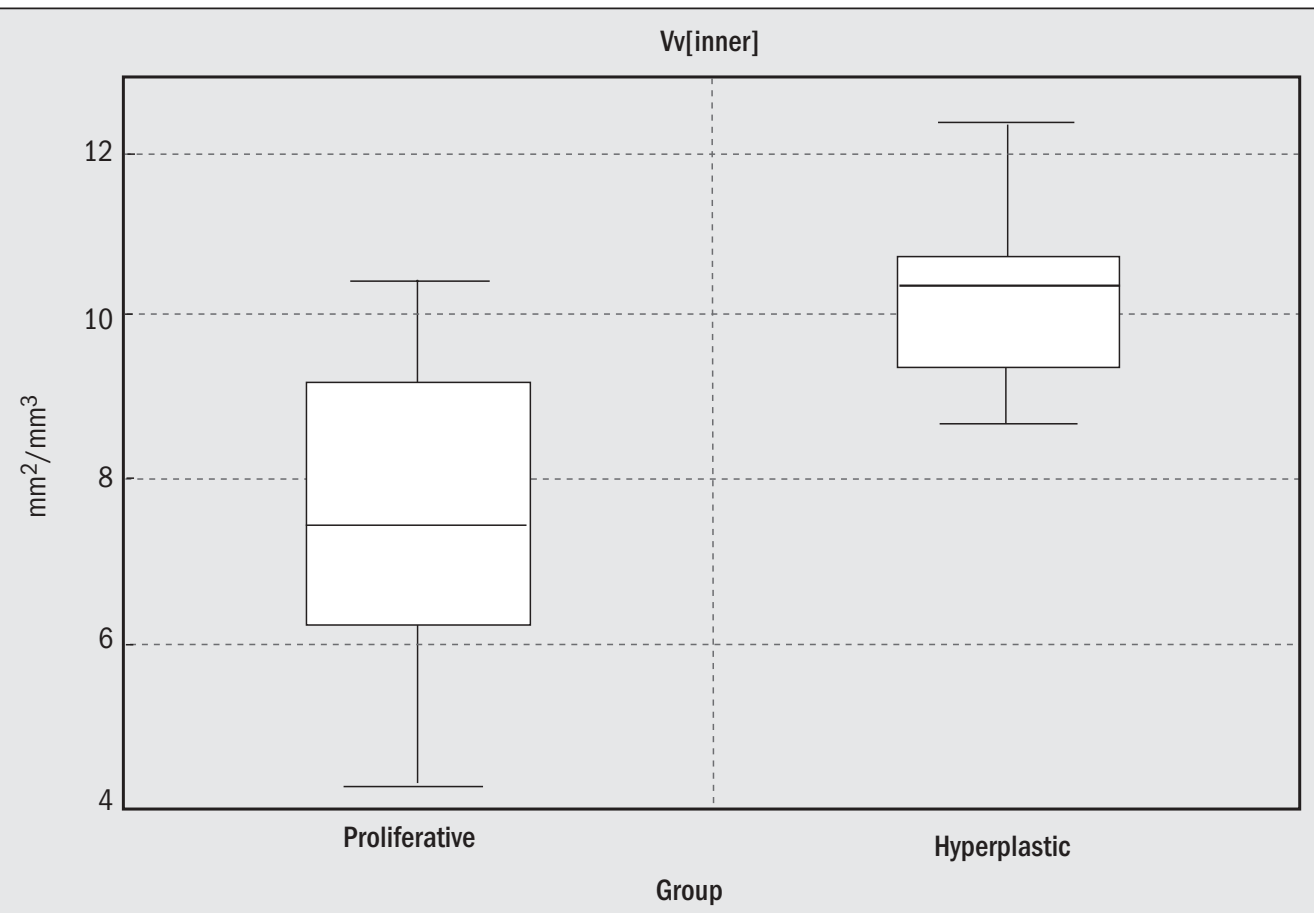

Figure 5 - Boxplot of the surface density of the inner glandular perimeter comparing the proliferative endometrium and the simple hyperplasia. Difference is significant $(p<0.05)$

Simple hyperplasia had smaller $\mathrm{V} v$ [stroma] than proliferative endometrium; this may be due, probably, to the relative decrease of the stroma caused by the increase in number and size of the hyperplastic glands. In simple hyperplasia the glands usually have a tendency to be crowded and with great diameters (luminal dilatation).
The literature is silent about this data concerning simple hyperplasia and proliferative endometrium. Baak et al. (4, $6,9)$, studying atypical hyperplasia and well-differentiated adenocarcinoma of the endometrium, observed that the $\mathrm{Vv}$ [stroma] was one of the most important parameters in this distinction and in the prognostic observation. The 
$\mathrm{Vv}$ [stroma] decreases in these cases because of the greater glandular assortment observed in adenocarcinoma cases, and its typical image of "back to back".

In the distinction between hyperplasia and adenocarcinoma the Sv[inner] has been pointed out as an important parameter (6). Present results have demonstrated significant difference of the Sv[inner] between simple hyperplasia and proliferative endometrium, that can be explained by the presence of epithelium infoldings into the lumen and also by the increase of the glandular internal perimeter (of the lumen), observed in the hyperplastic endometrium.

On the other hand, the Sv[outer] was not different between the two groups of patients. Baak et al. (6) found similar results concerning the glandular Sv[outer] in welldifferentiated and in the moderately differentiated carcinomas. This result could be explained by the fact that we have cystic dilatation of some of the glands in the simple hyperplasia when compared with proliferative endometrium and then, part of the outer surface of the cystically dilated glands may disappear outside the frame. Therefore, the outer surface per $\mathrm{mm}^{3}$ decreases, although of course, in the total tissue volume the total surface may still increase.

In the endometrium samples with hyperplasia, cystic dilatation of most of the glands (cystic hyperplasia) can explain the greater $V_{v}$ [lumen] found in simple hyperplasia cases. The morphological criteria to the diagnosis of simple hyperplasia (Kurman \& Norris' classification) (15) include architectural changes that correspond to the cystic hyperplasia (glands that are cystically dilated) and the complex hyperplasia (glands with budding and invagination). These criteria did not modify the analysis of the Vv[lumen]. Baak et al. (6) remembered that hyperplastic glands that present invagination have always associated a certain degree of luminal dilatation when compared to the proliferative endometrium.

The $V v$ [stroma] presented an opposite tendency to both $\mathrm{Vv}$ [epithelium] and $\mathrm{Vv}$ [lumen] because in a volume of the endometrium (test-volume) the densities that are related to the gland ( $\mathrm{Vv}$ [epithelium] $+\mathrm{Vv}$ [lumen]) and $\mathrm{Vv}$ [stroma] are complementary. This means that in simple hyperplasia cases compared to the proliferative endometrium the $\mathrm{Vv}$ [epithelium] and $\mathrm{Vv}$ [lumen] have a tendency to be greater while the $\operatorname{Vv}[$ stroma] has the tendency to be smaller in the first group.

We can conclude that the $\mathrm{Vv}$ [epithelium], $\mathrm{Vv}$ [stroma], $\mathrm{Vv}$ [lumen] and Sv[inner] allow to establish differences between the two groups of cases (simple hyperplasia and proliferative endometrium).

Stereology has been considered a time-requiring methodology. However, the new stereology and the facilities acquired by the semi-automatic equipment made this method non-fastidious and accurate (18). The present study demonstrated that stereology has interest in cases like simple hyperplasia and proliferative endometrium and can be used as a complementary method in the histopathological diagnosis. Quantification of histological images is easy and inexpensive and these techniques allow the pathologist to come to a definite diagnosis in an objective and reproducible way.

\section{Acknowledgements}

This work was partially supported by $\mathrm{CNPq}(52.23 .73$ / 95-0) and Faperj (E-26/170.315/95).

\section{References}

1. Artacho-Pérula, E.M. et al. H istomorphometry of normal and abnormal endometrial samples. Int. J. Gynecol. Pathol., 12: 173-179, 1993.

2.Ausems, E.W.M .A.et al.N uclear morphometry in the determination of the prognosis of marked atypical endometrial hyperplasia. Int. J. Gynecol. Pathol., 4: 180-185, 1985.

3. Baak, J.P.A. Further evaluation of the practical applicability of nuclear morphometry for the prediction of the outcome of atypical end ometrial hyperplasia.Anal.Q uant. Cytol. $\mathrm{H}$ istol., 8: 46-48, 1986.

4.Baak,J.P.A.The role of computerized morphometric and cytometric feature analysis in endometrial hyperplasia and cancer prognosis. J. Cell. Bioch., Supplement 23:137-146, 1995
5. Baak, J.P.A. et al. Architectural and nuclear morphometrical features together are more important prognosticators in endometrial hyperplasias than nuclear morphometrical features alone. J. Pathol., 154: 335-341, 1988.

6. Baak, J.P.A . et al. D iscrimination of hyperplasia and carcinoma of the endometrium by quantitative micro scopy - a feasibility study. $\mathrm{H}$ istopathology, 5:61-68, 1981.

7. Baak, J.P.A . et al. Q uantitative microscopical, computer-aided diagno sis of endometrial hyperplasia or carcino ma in individual patients. Histopathology, 5: 689-695, 1981.

8. Baak,J.P.A et al. Q uantitative morphology:methods and materials I. Stereology and morphometry. Europ. J. Obstet. Gynec. Reprod. Biol., 7/1: 43-52, 1977. 
9. Baak, J.P.A . et al. A ssessment of the risk on endometrial cancer in hyperplasia, by means of morphological and morphometrical features. Path. Res. Pract., 188: 856-859, 1992.

10. Colgan, T.J. et al. Predicting the outcome of endometrial hyperplasia by quantitative analysis of nuclear features using a linear discriminant function. Int. J. Gynecol. Pathol., 1: 347$352,1983$.

11. Fox, H. \& Buckley, C.H .The endo metrial hyperplasia and their relationship to endometrial neoplasia. $H$ istopathology, $6: 493-$ 510, 1982.

12. Fu,Y.S. et al. D igital imaging analysis of normal, hyperplastic and malignant endometrial cells in endometrial brushing samples. Anal. Quant. Cytol. H istol., 10: 139-149, 1988.

13. G usberg, S.The individual at high risk for endometrial carcinoma. Am. J. Obst. \& Gynec., 126:535-542, 1976.

14. Gusberg, S. \& Kaplan, A.L. Precursor of corpus cancer. Am. J. Obst. \& Gynec., 87:662-678, 1963.

15. Kurman, R.J. et al.The behavior of endometrial hyperplasia. A long-term study of "untreated" hyperplasia in 170 patients. Cancer, 56: 403-412,1985.

16. Langley, F.A. et al. Diagnosis making: error sources. In: Baak, J.P.A.; 0 ort, J. (eds): A M anual of M orphometry in Diagnostic Pathology, Berlin:Springer-Verlag, 1983, p. 6-14.

17. Mandarim-de-Lacerda, C.A.W hat is the interest of normal and pathological morphological research to be quantitative? The example of the stereolo gy. Braz. J. M orphol. Sci., 16(2): 131-139,1999.

18. Mandarim-de-Lacerda, C.A. M étodos Quantitativos em Morfologia. Rio de Janeiro: Ed/U ERJ, 1995.
19. M c Bride, J.M. Premenopausal cystic hyperplasia and endometrial carcinoma.J. Obstet.Gynaecol.Br.Emp., 66:288296, 1959.

20. Norris, H.J. et al. A comparative morphometric and cyto photometric study of endo metrial hyperplasia, atypical hyperplasia, and endometrial carcinoma. Human Pathol.,20: 219-223,1989.

21. Parazzini, F. et al. The epidemiology of endometrial cancer. Gynecol. Oncol., 41: 1-16, 1991.

22. Platz, C .E. \& Benda, J.A . Female genital tract cancer.Cancer, 75: 270-294, 1995.

23. Sherman, M.E.et al. p 53 in endometrial cancer and its putative: precursors evidence for diverse pathways of tumo rigenesis. Human Pathol., 26: 1268-1274, 1995.

24. Sherman, M.E. \& Silverberg, S.G. Advances in endometrial pathology. Clin. Lab. M ed., 15: 517-542, 1995.

25.Silverberg, S.G .et al. Endometrial carcinoma: clinical-pathologic comparison of cases in postmenopausal women receiving and not receiving exogenous estro gens. Cancer, 45: 30183026, 1980.

26. Skaarland, E. N uclear size and shape of epithelial cells from the endo metrium: lack of value as a criterion for differentiation between normal, hyperplastic, and malignant conditions. J. Clin. Pathol., 38: 502-506, 1985.

27. W eibel, E.R. et al. Practical stereological methods for morphometric cytology. J. Cell. Biol., 30:23-38, 1966.

28. W eibel, E.R. Stereological methods. In: Practical methods for biological morphometry. London:A cademic Press, vol 1,1979.

29. W elch, W.R. \& Scully, R.E. Precancerous lesions of the endo metrium. Human Pathol., 8: 503-512, 1977.

\section{Correspondence to}

Elyzabeth Awad

Universidade do Estado do Rio de Janeiro (UER))

Centro Biomédico - Lab. de Morfometria

(Prof. Mandarim-de-Lacerda)

Av. 28 de Setembro 87 (fundos)

CEP 20551-030 - Rio de Janeiro-Rl - Brasil

Tel./fax: (+55 21) 2587-6416/6139

e-mail: mandarim@ueri.br 